\title{
Saccharomyces cerevisiae
}

National Cancer Institute

\section{Source}

National Cancer Institute. Saccharomyces cerevisiae. NCI Thesaurus. Code C14271.

A species of unicellular fungus used as a research subject and in baking and beer brewing. 